\title{
NOTES ON THE NEW NEW ZEALAND EARTHQUAKE LOADING PROVISIONS
}

\author{
D. Kolston*
}

\section{ABSTRACT}

The paper indicates various aspects of the new earthquake loading provisions which are at present still in draft form.

Important changes from the previous code include requirements regarding ductility, energy dissipation, capacity design, concurrency effects, foundation design, torsional effects and separation of elements. The seismic design coefficients for buildings and part of buildings are related to zoning, building period, subsoil, importance factors, structural type, structural material and risk factors. Dynamic analysis is directly related to the codified equivalent static force spectrum.

\section{INTRODUCTION}

Since the beginning of 1971 the loadings committee of the New Zealand Standards Institute has been engaged on the revision of the present Chapter 8 of N.Z.S.S. 1900 "Basic Design Loads".

With the introduction of zoning, determination of building period and consideration of ductility, Chapter 8 represented in 1965 a radical departure from the previous N.Z.S.S. 95, Part IV.

In subsequent amendments, some of these concepts had been further enlarged or revised but it was agreed among designers in general that a drastic revision of the code was urgently required to incorporate the increased knowledge which has become available in the last 10 years.

Such a revision. would therefore take into account the evidence gathered from recent earthquakes and the ever increasing amount of research and technical literature on the subject which has become available over the past 10 years.

At present it is left to the individual informed designer to decide on the desirability of the inclusion of a particular new consideration or provision in his designs.

For the un-informed designer, the situation is more serious because the blissful ignorant can be a menace to himself and others. Without codification this leads to widely varied standards. Commercial competitive pressures could favour the less informed designer and prevent the application of sound engineering principles.

This aspect can be particularly important in a "Design and Build" situation which is at present much more prevalent than, say, 10 years ago.

Up-to-date provisions should certainly assist informed designers in this regard.

In accordance with the new policy adopted by the Standard Association of New Zealand

* Consulting Engineer, Structon Group Architects, Wellington.
(S.A.N.Z.), the standard will consist of a Bylaw portion called "General Design and Construction Requirements and Design Loadings" which only contains general and legal requirements, and a code of Practice which forms a "means of compliance" approved to be used as meeting the Bylaw requirements.

The "means of compliance" format has been adopted by S.A.N.Z. for all building Bylaws for two main reasons:

(a) to reduce the legal complications facing a local authority in the adoption of the Standards Model Building Bylaw,

and

(b) to enable technical requirements to be written in a more flexible format than appears to be possible within a Bylaw.

At the time of writing these notes, both the Bylaws portion and the code of Practice have appeared in draft form but neither of them have been finalised.

Completed first drafts were circulated for comment during the months of March to May 1973. Some 150 comments have been received regarding the earthquake provisions alone, which shows the magnitude of the interest taken in the subject by the engineering fraternity at large. Unfortunately, allied professions like architects, whose designs are vitally affected by codes such as these, do not appear to show much interest.

As a result of these comments, further available literature, and consideration by the committee, amended drafts have been prepared and the notes in this paper are based on the January 1975 version.

It is assumed that conference participants will have copies of the latest drafts at the time of the conference, otherwise relevant tables etc., will be distributed at the time.

Seismic design is intimately linked with code provisions for gravity loads. The code of practice incorporates the 
gravity loadings and load factors to be used in design. The revisions of these items will effect the design of the chosen energy absorbing elements, which consequently effect the other structural elements.

Commentary on clauses in the code of Practice are printed on the facing page of the clause considered.

This format follows the method adopted by British Codes of Practice.

Although more costly as far as the use of paper is concerned, the state-of-the art in seismic design makes the commentary an important aspect of the code.

The low sales figures of the present separate booklet MPI2 "Commentary on Chapter 8" suggests that designers are not necessarily aware of the reasons for - and the limitations of - the various present requirements. As the present commentary serves the dual purpose of simultaneously providing more detailed information and avoiding the codification of more arbitrary matters it is of importance that designers are constantly made aware of their existence. It was therefore considered that the relatively small extra expense would be justified in the interest of good design.

\section{GENERAL REMARKS} that:

The Bylaw portion of the Standard states

"8.1 The design and construction of any building shall be such that:

(a) All foreseeable loads likely to be sustained during the life of the building will be sustained with an adequate margin of safety;

(b) Deformation of the building will not exceed acceptable levels (under these loads);

(c) In foreseeable events that occur occasionally, such as moderate earthquakes and severe winds, structural damage will be avoided and other damage will be minimized;

(d) In foreseeable events that occur very seldom such as major earthquakes and extreme winds, collapse and irreparable damage will be avoided and the probability of injury to-or loss of life of people in and around the building will be minimized.

8.2 Buildings that comply with N.Z.S. 4203 "Code of Practice for General Structural Design and Design Loadings" shall be approved as complying with the requirements of clause $8.1 "$.

In the first clause, the Bylaw portion defines the essential requirements for the design and construction of a building in regard to loadings.

The second clause indicates the code of practice which at this stage forms an acceptable means of compliance which means that it is considered that this document provides reasonable technical requirements to satisfy that Bylaw.

It is understood that other standards might later also qualify. Our notes today are confined to the N.Z.S. 4203 Code of Practice.

The circulated drafts of the code have been produced in four parts as follows:

Part 1: General Structural Design and Design Loadings.

Part 2: Dead and Live Loads

Part 3. Wind Loads

Part 4: Earthquake Provisions.

In the final version, these parts will be combined into one document.

Our notes are confined to Part 4, apart from some relevant observations related to capacity design etc which is obviously also influenced by load factors (defined in part 1 ) and loadings (defined in part 2).

The committee considers that the earthquake provisions of Part 4 comply with the intention of the Bylaw mainly for two reasons:

1. The absence of major earthquakes in New Zealand in the last 10 years in areas where current design practice could be tested does not allow for a significant change in the selection of the average seismic code loads. This means that there is no evidence to suggest that the level of present provisions is basically in error.

2. Overseas earthquakes have confirmed the need to incorporate in the design of structures the concept of capacity design (San Fernando), ductility provisions (San Fernando and Caracas), increased loadings for less dutile structures (Tokachi-oki), and the avoidance of the use of non-ductile elements which alter the strcutural behaviour (Caracas).

The importance of ductile detailing for framed structures is now generally realised by designers.

At this stage, and in view of 1 . above, major changes for ductile structures have not been adopted but the structural type factor for this category has been reduced by $20 \%$. This is an effective reduction in horizontal load by the same amount. A further reduction is not warranted unless it can be determined that the basic design loads are excessive because for a given earthquake load on the structure the ductility demands are increased proportionally to the lowering of the design loads.

Code requirements are mainly devoted to the equivalent static force analysis and the alternative dynamic spectral modal analysis which is permitted by the code is now related to the value of the seismic design coefficient $C_{d}$ for each mode. This will ensure that the values for damping and ductility which are inherent in the choice of this coefficient for the static method will automatically be 
reflected in the spectral modal analysis. This also obviates the need for a choice of actual damping and ductility values for various materials and structures. At present the literature and various available codes supply such conflicting information for these parameters that codification is considered to be premature.

For instance, the draft recommendation by the Building Research Institute of Japan on the design seismic forces for Japan gives damping ratio's of $1 \%$ for steel and $3 \%$ for reinforced concrete.

The Los Angeles proposed building code amendment of April 28, 1972 indicates ratio's of $2 \%$ to $7 \%$ for steel and from $5 \%$ to $10 \%$ for concrete mainly depending on the character and extent of non-structural elements.

Every designer knows that such possible arbitrary variations makes nonsense of any pretense that a spectral modal analysis would be superior to the static code provisions for regular buildings.

The most important change introduced by this code is the extension of the previous formula $\mathrm{V}=\mathrm{KC} \mathrm{W}_{\mathrm{t}}$ into $\mathrm{V}=\mathrm{C}$ I $\mathrm{S} \mathrm{M} \mathrm{R} \mathrm{W}_{\mathrm{t}}$.

The single term $\mathrm{K}$ has thereby been extended to a multi-term evaluation of several aspects which were previously combined into one or had not been considered at the time.

The actual choice of factors has been based on an apparent logical relationship between them rather than on actual factors. It is realised that the apparent sophistication of the formula would then appear not to be justified. However, the previous single factor represented a combination of considerations and designers were not necessarily aware of these.

The new appraoch will draw the designer's attention toward the need of a choice between the various alternatives which are available.

Such a conscious choice should stimulate further investigation and hopefully, better design than before.

In this respect, even arbitrary rules sometimes serve a good purpose. The classical example of this is the previous arbitrary height limit on the use of reinforced concrete buildings which led to considerable research and resulted in our appreciation of ductility requirements.

The simplicity is gone but our structures should improve because of the lower coefficients which may be used for better structures.

The design of parts and portions of buildings is further extended to incorporate not only the likely behaviour of the building but also the characteristics of the part under consideration. This section is seemingly complicated but the factors can be readily established for a particular building. One of the advantages of the method is again that the designer is made aware of the various choices which are available. Limits are set which are related to the estimated likely response from an El-Centro type earthquake, and the designer could, of course, use the higher limits if he so desires and not bother about the more complicated assessment.

The original drafts included a provision for vertical earthquake effects on columns and shear walls. This requirement was dropped because at this stage it is unknown to what extent vertical accelerations (.2 to . $3 \mathrm{~g}$ recorded for San Fernando) coincide with the horizontal design earthquake effects and also what the amplification effect is of the vertical forces up the height of a building.

In particular the Caracas earthquake has shown the importance of the separation of nonstructural elements from the structure. The previous code had no requirements in this respect as long as the interstorey deflection was limited to .0025 of the storey height $(1 / 400 \mathrm{~h})$ for the design load. This requirement would accept an actual deflection exceeding $25 \mathrm{~mm}$ per floor with resulting nonstructural damage and, perhaps more important, a possible marked effect on the behaviour of structural elements.

For this reason, non-structural elements are now required to be separated from the structure when the computed inter-storey deflection exceeds .0003 of the storey height. In practice this means that all framed structures will have such separation provisions.

\section{DESIGN PRINCIPLES}

We will discuss the following items which form the first technical part of the code which deals with basic design requirements.

\subsection{Symmetry:}

This is really the most fundamental starting point for good earthquake resistant design. Even for symmetrical structures, recent studies have indicated that torsional responses are greater than assumed in the past, also due to relatively apparent minor variations in subsoil conditions. The new code has therefore drastically changed the present torsional provisions.

The uncertainties which exist with the design of regular buildings are greatly enhanced as soon as the structural elements of a building are dissimilar. These uncertainties certainly will have to be avoided when the concept of capacity design is used to ensure that primary structural elements remain intact. The commentary makes the point on the choice of the correct mathematical model for a complex arrangement of combinations of various structural elements. At this stage, for instance, there is still considerable doubt about the number of hinges which develop in beams up the various floors in a building during an earthquake. The assessment of the interaction between the relative hinged or cracked strength between shear walls and frames is virtually impossible.

In practice, the architectural design of the building makes it often impossible to obtain a symmetrical planned layout. Engineers will now introduce separations between the 
structure and walls which could act as unfavourable elements in the building design. The introduction of disconnected light weight materials has the effect of reducing the damping of the building with resulting increased interstorey deflections and a general different response of the buildings to the seismic disturbance because of lower damping values.

\subsection{Ductility:}

The code clause on ductility is similar to the clause in the previous code. The commentary clause specifies the concept of "adequate" ductility. This "adequate" ductility is presumed to be provided if designers follow the provisions in the various material codes.

For the concrete code, provisions have now been in general use for some years and are constantly being updated. Provision for structural steel, masonry and prestressed concrete are in the process of being formulated at present.

In practice the provisions are only very definite for columns and beams. Even here more experimental investigation is still required. Adequate ductility of shear wall systems is at present less clear.

The commentary stresses the point that the ductile provision are based on the assumption of a structure consisting of symmetrical frames without sudden changes in storey stiffnesses.

For other buildings, the commentary refers to the necessity to determine maximum section curvature ductility demand by a nonlinear analysis. Such an analysis should take account of earthquake imputs appropriate to the site.

It is clear that this procedure can only be contemplated to be used in very exceptional cases and that the "state of the art" would still require a most careful assessment of the results. The smallest shift in the calculation of the building period might produce results with a variation approaching $100 \%$.

The commentary also provides a more practical alternative which is based on the equivalent deflection criterium for the irregular framed building, based on a ductility factor of 4.

The acceptance of a reduction of $20 \%$ in the horizontal load carrying capacity of the building in at least eight load reversals is in line with the acceptance of a reduced ultimate moment capacity of a confined section of $80 \%$ of the maximum moment which the section can develop.

In this way, the recommendation is related to the present standards for member ductility.

It should be realised that the procedures indicated in the commentary for irregular framed buildings are really quite arbitrary. They are based on work carried out at

Canterbury University by Park, Blakeley, Kent and others.
Details are provided in the papers referred to in the Reference list.

For many designers, the commentary will still be quite obscure. This is probably just as well if it ensures that designers will not venture too far into the unknown without realising the pitfalls which exist.

Elements within the building which do not form part of the earthquake resisting structure must be investigated to ensure that these elements can keep on functioning under the specified deflection of four times the deflection at first yield.

The point is, that even for elements which are purely supporting gravity loads, it may be necessary to apply the ductility provisions to these members and to examine preferable hinge positions. More brittle elements require special attention.

\subsection{Energy Dissipation and Capacity Design:}

Earthquake records show that building structures are called upon to withstand loads far in excess of the loadings in the code.

These loads are resisted inelastically by yielding of structural elements.

For the desirable behaviour of a structure, it is important that such inelastic yielding (or hinge forming) occurs in the elements of the structure which will not give rise to any subsequent undesirable behaviour such as could occur if hinges were to develop in all the colums of a particular storey in a building.

In such a case, that building storey could collapse while the rest of the structure is still in relatively good shape. If this storey happens to be the ground floor of a 20 storey building, the fact that only 5\% of the building behaves in this way will still be of small comfort to the occupants, owner and insurer of the building.

For this reason, the concept of capacity design has been made mandatory in the code. This applies to the design of beams in framed structures, diagonal braces in braced structures, to various elements of ductile shear walls and to the foundations of all earthquake resistant structures.

In essence, capacity design will ensure that the structures will behave as intended and desired by the designers.

For instance, in the design of building frames, the desirable primary energy dissipating elements are the beams in the frames.

The design of these beams is determined by the loadings which have been specified in the code and using the design procedures specified in the material codes.

The structural elements such as columns are then designed using the effects (loads, moments, shears) resulting from the designed beams. Such columns should have a sufficient reserve strength capacity to ensure that the desired hinges will indeed occur in the beams 
rather than in the columns.

The exact level of this over-capacity will be determined in the various material codes and will be influenced by the assessment of present existing under-capacity factors.

In this respect, the revision to the load factor equations used for design are of importance. For earthquake conditions, the equations are:

$$
\begin{aligned}
& \text { for gravity load: } U=1.4 \mathrm{D}+1.7 \mathrm{~L}_{\mathrm{R}} \\
& \text { for seismic load: } \\
& \text { either } \quad U=1.00 \mathrm{D}+1.30 \mathrm{~L}_{\mathrm{R}}+\mathrm{E} \\
& \text { or } \quad U=.9 D+E
\end{aligned}
$$

The significant change here is the introduction of $\mathrm{L}_{\mathrm{R}}$ in the load equations. $L_{R}$ represents the reduced live loading to be taken on a building element.

As explained above, the design of beams is determined by the specified loadings. In the present Chapter 8 , in the design of main beams for office buildings, the live load on a single span is allowed to be reduced by 5 per cent for each $500 \mathrm{sq}$. ft. of supported floor, up to a maximum of 25 per cent.

In the new loading code, the loading $L_{R}$ is expressed as:

$$
L_{R}=R \cdot L_{U} \cdot A \text {. }
$$

and for $A>150$ square foot

$$
\left(0.77-.23 \frac{\mathrm{Du}}{\mathrm{Lu}}\right)<\mathrm{R}>(1-0.0008 \mathrm{~A})
$$

For a 500 sq.ft. supported floor, therefore, the reduction factor is not $5 \%$ but a minimum of $40 \%$, depending on the $\mathrm{Du} / \mathrm{Lu}$ ratio.

Because the beams in the frames will be designed for a substantial lower live loading in comparison with before, significant economics in the right directions will result.

Capacity design requires that building elements are constructed as intended by the designer. In the design of frames, for instances, the introduction of larger diameter bars in a concrete beam can have serious consequences if the designer is not made aware of the change.

The code gives detailed requirements and recommendations for beams and columns of ductile frames.

Generally the commentaries are related to reinforced concrete design and are based on the most recent results of tests. Details of design will be left to the material codes committees.

It is generally realised that columns should be designed to have adequate overcapacity to avoid the formation of hinges.

For special cases such as 2 storey buildings, top stories of multistorey buildings, and for adequately redundant structures with no - or a low axial compression in the column, the requirements have been relaxed.
For columns, it is vitally important that a shear failure is avoided. Shear calculations based on the formation of hinges in the top and bottom of columns will obviously fulfill this requirement.

Theoretical considerations applied by K.E. Williamson appear to indicate that ultimate column shears will never exceed 2 to 2.5 times the calculated horizontal load $E$ on a building and this would therefore then be the maximum shear to be allowed in the design of columns.

\subsection{Foundation Design:}

Foundation design is required to be part of the capacity design for yielding structures, but some relaxation is permitted.

These relaxations are considered to be appropriate because the interaction of the structure and the foundation have not been explored to the same extent as other building elements. It is, for instance, quite possible that the energy dissipation due to rocking of walls will result in a reduction of response which is quite beneficial to the overall structural behaviour of the building.

Some of these relaxations are:

1. A factor of safety 1.1 for soil pressures is considered to be adequate when design loadings on the soil are calculated from yield capacities. This is a marginal safety margin which is considered to be adequate for this ultimate loading condition.

2. Uplift of $25 \%$ of column footings in any direction is acceptable.

3. The limit for any foundation system design is set at a level which corresponds to the effects from a horizontal force which is roughly speaking equal to double the Chapter 8 code level of design $(\mathrm{SM}=2)$.

For those structures, where the design is determined by factored loads, such as non-ductile shear walls, a factor of safety of 1.5 is recommended for the soil strength and the soil design allows for the use of a rectangular stress block.

Because the structural factors for nonductile yielding shear walls are 1.6 times higher than in Chapter 8 , the stability of these walls will create special problems in comparison with present day practice. The code allows an arbitrary increase of $20 \%$ of gravity loads as far as stability calculations are concerned. This concession is also considered reasonable because spectral modal analyse of shear walls indicate that the overturning moments appear to be appreciably lower than is indicated by static formulae.

\section{EQUIVALENT STATIC FORCE ANALYSIS}

As indicated in the General Remarks of these notes, the code is mainly devoted to supplying requirements, coefficients etc., 
which are related to an equivalent static force analysis.

This part of the code has deliberately been placed ahead of the dynamic approach provisions to emphasise the primary importance of the static analysis in the mind of the designer.

\subsection{Multi-term evaluation}

The total seismic force $V=C_{d} W_{f}$ in which $C_{d}=$ C.I.S.M.R. replaces the previous formula $\mathrm{V}=\mathrm{KCW}_{t}$, and with this formula, the factor $K$ which was used in Chapter 8 has been replaced by the multi-term evaluation factor $\mathrm{C}_{\mathrm{d}}$.

The factor $C_{d}$ determines the appreciation of the designer of the effect of the design earthquake on the structure.

The effects are determined by the location, amplification factor, damping, structural type and material used.

Further considerations are the type of occupancy and the risk involved in case of failure.

The factors are made up as follows:

\section{$C=$ Basic Seismic Coefficient}

$C$ is generally similar to the previous design spectrum given in Chapter 8 when it is realised that the present coefficients incorporate the previous load factor of 1.25 .

The previous coefficients were given for hard and intermediate soils only and the spectrum in fig 1 now includes the recommended minimum values for flexible subsoils as specified in the code.

The inclusion of the soil-type factor should be regarded as a first step approach towards the consideration of microzoning effects, which is in line with most codes in other countries.

The revision is most significant for zone $C$ for longer period buildings. This is consistent with the experience that flexible buildings on soft soils are subject to higher accelerations for distant earthquakes.

For very high intensity earthquakes amplifications may not be so great due to plastic deformation in the soft soil.

Detailed considerations on various aspects of the subsoil considerations are given in the commentary.

\section{$I=$ The Importance Factor}

The previous code provision between "public" and "non-public" buildings has now been extended with a class of public buildings which are considered to be required to be functional immediately after seismic disaster. These essential buildings are listed in the commentary and include ambulance centres, fire stations, hospitals, and the like. For these buildings it is also of particular importance that the secondary damage will not render the building nonfunctional. In this regard safe concrete canopies to hospital entrances are just as important as the structural framing system of the hospital itself.

\section{$S=$ Structural Type Factor}

Nine main categories of structural types have been listed and the value of $S$ varies from 0.8 for ductile frames and ductile coupled shear walls, to 2.5 for diagonal tension bracing up to three stories.

For some types, the committee considered it appropriate to request that a special study be made of the structure, for instance for diagonal tension bracing over three stories or for a possible combination of frames and bracing. At this stage, there is simply no reliable information available.

In other cases, factors are given but designers have the opportunity to carry out a special study to determine the $\mathrm{S}$ factors.

The factors recognise the value of ductile detailing both for frames and shear walls. The $\mathrm{S}$ factor for pure shear walls is double the factor for ductile structures (.8 versus 1.6 ). This is in line with the S E A O C provision of long standing.

Requirements for the various categories are given in the commentary to the code. Details for ductile coupled shear walls include the requirements for coupling beams and the vertical walls.

The code also specifies the minimum length $(1.5 \mathrm{~m})$ for ductile shear walls and shear walls designed to dissipate a significant amount of seismic energy. The dimensional requirements are obviously arbitrary but it is considered necessary at this stage to ensure that sufficient material is available to prevent a shear failure of the wall.

The commentary indicates to the designer that a capacity design for shear derived from the flexural capacity of the wall might underestimate the seismic shear.

This is due to the fact that the resultant seismic force of the various modes might be located at a lower level than the triangular pattern suggested by the code.

It is therefore suggested that the design shear for walls be based on a factored load approach using $S=2$. (again in line with the $S$ E A O C provisions).

A separate table is given for the various forms of single storey cantilevered structures such as columns and walls.

For ductile cantilevered columns, the 
$S$ factors are similar to the previous coefficients in Chapter 8 .

Coefficients for face loaded walls have been varied for walls with double reinforcing and single reinforcing. This recognises that doubly reinforced walls are more ductile than walls with single reinforcing.

The S factor for garden walls is lower than for boundary walls because a collapse of a garden wall will generally not be a hazard to the public.

$M=$ Structural Material Factor

These factors vary from . 8 for structural steel and timber shear walls to 1.2 for prestressed concrete and masonry.

The value of 1 for concrete has virtually been used as the basic coefficient and other values have been scaled up or down from this unit value.

It is generally recognised that steel is a better structure seismic material and that the performance of masonry relies to a large extent on standards of workmanship on the site.

The commentary contains a warning about the use of prestressed concrete and the $20 \%$ allowance over reinforced concrete is considered to be a minimum.

Detailing of prestressed concrete will have to be similar to the ductile detailing requirements for reinforced concrete.

In general, the material factors are intended to supply interim values only, depending on material standards for revision if required. This would in particular apply if the intentions of the earthquake provisions cannot be fully realised by the various material details.

$\mathrm{R}=$ Risk Factor

For most buildings this factor equals 1 and the highest factor of 3 applies to structures containing toxic liquids.

It was considered that a modest increase (of 10\%) was appropriate for assembly buildings and buildings containing more than 1000 people. This is in line with some overseas practice, for instance, in Japan.

$W_{t}=$ Total Reduced Gravity Load

Note that this factor has been revised and generally reduced for loadings up to $5 \mathrm{kPa}\left(100 \mathrm{lb} / \mathrm{ft}^{2}\right)$

Wt can now be taken as:

$\mathrm{D}$ when $\mathrm{L}<1.5 \mathrm{kPa}\left(<301 \mathrm{~b} / \mathrm{ft}^{2}\right)$

and generally as

1. ID when $1.5 \mathrm{kPa} \leqslant \mathrm{L} \leqslant 5 \mathrm{kPa}$

\subsection{Concurrency}

The code introduces the requirement that columns and column-beam joints for columns framed in both directions shall be designed for the earthquake attack in both directions concurrently.

Concurrency on such columns takes place because, for the beams designed to code loadings, and with a ductility factor of four, total horizontal displacements are approximately four times the initial yield displacement during a major earthquake.

For an earthquake attack which is under an angle of, say, $45^{\circ}$ to one of the principal directions, the beams in both directions will yield and the column will be subject to the maximum yield moments in both directions at the same time.

The effect of concurrency can be avoided by the introduction of two dimensional seismic frames in each direction, peripheral frames without corner columns etc.

\subsection{Distribution of horizontal forces}

The clause is generally similar to the clause in the previous code and will result in a triangular distribution of the base shear for a regular structure of uniform weight per unit height.

This distribution is amended as before for more flexible structures where the height to depth ratio of the horizontal force resisting system is equal to or greater than 3 .

This takes into account the effects of higher modes for these more flexible structures.

For still more flexible buildings like chimneys and smoke stacks this distribution is further loaded towards the top as required in Chapter 8 and for the same reason.

The distribution provisions for set backs have been extended. When the plan dimension of the tower in each direction is equal or more than 75 of of the corresponding plan dimension of the podium, no special distribution provisions are required.

In other cases, the modes of vibration of tower and podium influence both parts of the building. The whip effect from the tower is simulated by the requirement that $10 \%$ of the horizontal base shear is to be concentrated at the top of the tower.

The same requirement applies to the distribution over the height of the podium unless the mass of the tower is insignificant ( $10 \%$ of the total mass), when all the base shear is allowed to be distributed as for a building without setbacks.

The setback provisions are obviously very approximate and for important buildings with setbacks, a dynamic study should be made.

\section{4 Torsional provisions}

In chapter 8 , horizontal torsional moments were determined by the sum of the computed static eccentricity and an arbitrary 5\% of the maximum building dimension perpendicular to the direction of loadings.

The new Code static formulae for torsion 
are $e_{d}=1.7 e_{s}-e_{s} 2 / b+0.1 b$

or

$e_{\mathrm{d}}=\mathrm{e}_{\mathrm{s}}-.1 \mathrm{~b}$.

whichever is the more unfavourable.

These equations take into account

1. The dynamic amplification of torsional effects.

2. The angular acceleration of the soil

3. Accidental eccentricities of stiffness

4. Accidental eccentricities of mass

5. Failure of structural elements in a severe earthquake.

The equations have been partly derived from results given in Newmark and Rosenblueth "Fundamentals of Earthquake Engineering" (1971) and partly from computations carried out for a number of typical cases by D.G. Elms.

Generally, the arbitrary value decreases for longer period buildings and increases for periods smaller than .3 secs. The chosen value of .1 is the average recommended.

This appears to be consistent with measured effects for apparent symmetrical buildings.

For flexurally ductile systems, earthquake loads can be re-distributed up to a maximum of 15\% of the load resisted by any element. This consideration will tend to diminish the adverse effect of the increased torsional requirements for symmetrical buildings.

Torsional effects are very difficult to determine and it should be stresses that the first principle of earthquake resistant design is to achieve symmetry.

The static formulae are not intended to be used for buildings with irregular plan forms.

Such forms are to be avoided by the introduction of seismic separations between the sections of the building and so obtain the required symmetry.

\subsection{Small Buildings of Limited Ductility}

The purpose of this clause in the code is to allow designers to design small framed buildings when the dimensions of the columns and beams do not comply with the ductility requirements in the material codes.

Class I buildings have been excluded, the floor areas are not to exceed $1400 \mathrm{~m}^{2}$ and heights have been restricted to $9 \mathrm{~m}$ (or 2 stories) in zones $\mathrm{A}$ and $\mathrm{B}$ and to $13.5 \mathrm{~m}$ (or 3 stories) in zone $C$.

Two design procedures have been indicated, a complete elastic design procedure and a design procedure where a low in-elastic demand from the structure is still required.

For the elastic design, the factor $C_{d}$ in the formula $\mathrm{V}=\mathrm{C}_{\mathrm{d}} \mathrm{W}_{\mathrm{t}}$ includes a factor of 6 in lieu of the structural type factor $s$.
The formula therefore becomes $C_{d}=6.0$ C.I.M.R.

The factor of 6 has been chosen because building capacities have to be very large to escape major damage in strong earthquakes. The factor corresponds to a horizontal static design load of approximately $1 \mathrm{~g}$, which is the response to a $1.25 \mathrm{El}$ centro N.S. ground motion acceleration spectrum value for a building with $2 \%$ damping.

Such elastically designed buildings do not need to comply with any of the code provisions. Foundation design is relieved from the high load factor because the code generally accepts that no foundation system needs to be designed for a horizontal force resulting from S.M. greater than 2 .

The second type of small building is the building from which a certain amount of inelastic behaviour can be expected.

Two types of such buildings are allowed to be used, either structures with wide columns $(800 \mathrm{~mm}$ wide) or structures with ductile columns complying with the ductility requirements of the materials code and deep beams ( $750 \mathrm{~mm}$ deep).

For these buildings, the effective $\mathrm{S}$ factor has been taken as 2.4 up to values of $\mathrm{C}_{\mathrm{d}}$ of .24 and a value of $\mathrm{C}_{\mathrm{d}}=.24+$ $.8 \mathrm{ClMR}$ for $\mathrm{C}_{\mathrm{d}}>.24$.

In practice, the values of the $c_{d}$ coefficients would be less than one half of the coefficients for the elastic design.

It is considered that the minimum specified member dimensions will result in a higher damping factor which justifies this reduction.

The combination of ductile columns and deep beams is also superior to the brittle structure of elastic design.

The level of loading for these small structures is such that few designers will use this part of the code and will be able to prove to their clients the advantages of complying with the provisions for ductile frames.

The main purpose of the clause might therefore be to stress the importance of such a ductile design and to emphasize the very real high horizontal loadings which result otherwise.

\subsection{Parts or Portions of Buildings}

Parts of buildings are structural elements of which the behaviour during an earthquake is affected by the building response. When the principle of multiterm-evaluation is applied, this term therefore consists of two elements.

One of these elements relates to the nature etc., of the part of the building itself and the other element to the nature of the building supporting the part.

In contrast to the previous Chapter 8 standard, where the horizontal forces on parts of buildings were only related to the oart itself (with the formula $\mathrm{F}_{\mathrm{S}}=\mathrm{K} \mathrm{C} \mathrm{W}_{\mathrm{S}}$ ), 
the new code determines these forces with the formula

$\mathrm{F}_{\mathrm{S}}=\mathrm{C}_{\mathrm{p} 1} \mathrm{C}_{\mathrm{p} 2} \mathrm{~W}_{\mathrm{p}}$

$\mathrm{C}_{\mathrm{pl}}=\mathrm{K}_{\mathrm{p}} \mathrm{R}_{\mathrm{p}} \mathrm{C}_{\mathrm{d}}$ of which

$\mathrm{C}_{\mathrm{p} 2}=\mathrm{S}_{\mathrm{p}} \mathrm{M}_{\mathrm{p}}$

The factor $\mathrm{C}_{\mathrm{p} 2}$ is the product of the structural factor $\mathrm{S}_{\mathrm{p}}$ and the material factor $\mathrm{M}_{\mathrm{p}}$ of the part.

The $S_{p}$ factor varies from 1 to 3 generally depending on the relative ductility of the

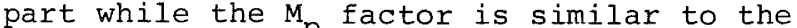
materials factor ${ }^{\mathrm{p}}$ which applies to buildings.

Note that the ductility rating of parts have been chosen based on assumed or known performance during earthquakes and not on the stringent detailing requirements for primary members.

The inclusion of the $\mathrm{C}_{d}$ coefficient in $c$ relates the part to the behaviour or the blilling. The formula accepts that the force on the part is determined by the acceleration response on the building by the earthquake.

This assumption could be questioned but appears to be logical for fixed items. For loose objects like furniture etc., it would appear that velocity response is the more important consideration.

Maximum accelerations for a building are determined by its yield capacity for yielding structures or by the elastic damped response for non-yielding structures.

Theoretically, therefore, the $c_{d}$ value should provide the fuse which determines the maximum loading on the part.

Due to the standards of design, undercapacity factors and general uncertainties, it is necessary to assume a building overcapacity of $50 \%$.

The factor $\mathrm{K}_{\mathrm{p}}$ is related to this consideration and is therefore generally 1.5, increasing to 3.0 at the top of be building, (assuming a triangular distribution).

The risk factor $R$ for parts is partly determined by the consideration of redundancy (as for cantilever versus non cantilever structures) and partly by the possible results of danger at failure. These factors vary from 1 (no particular consideration required) to 2 for certain cantilevers for toxic liquid containers, furnaces etc.

The values of $R_{p} K_{p}$ have been tabulated in table 6 .

This table also indicates the minimum and maximum values which are to be used for the product of $\mathrm{C}_{\mathrm{pl}} \mathrm{C}_{\mathrm{p} 2}$. Both values are determined from the maximum forces which parts are likely to have to resist from the amplified design earthquake, adjusted for their relative ductilities.

The limits indicated are for zone A, class III buildings and are to be adjusted for I and for seismic zones generally as applies to the building structure itself.

\subsection{Deformations and Separations}

The present Chapter 8 allows for a $0.25 \%$ interstorey deflection under present code loads without an allowance being made for the separation of non-structural elements.

Ductile behaviour of the structure will cause deflections under the design earthquake which will be 3 to 4 times greater than this calculated deflection.

Non-structural damage represents often the most significant monetary loss in a moderate or severe earthquake.

Inadequate separation distances can also significantly affect the behaviour pattern of structural elements. The typical example is the effective shortening of columns by masonry panels.

The $.25 \%$ allowance in Chapter 8 represents an interstorey deflection of $8 \mathrm{~mm}$ for a storey height of $3.3 \mathrm{~m}$.

With a ductility factor of 4 , these provisions will result in a significant amount of structural damage.

The new Code limits the interstorey deflection to $.03 \%$ of the storey height.

Although the loadings of the two standards are not strictly comparable because of the introduction of various new factors in the new code $(S=.8$ for ductile frames, $M=.8$ for structural steel, $C$ new $=1.25 \times \mathrm{C}$ old ) the new limit will reduce the previous allowance to a level which will make it necessary to separate nonstructural elements for all but the most rigid buildings.

In the past, frames were often dimensioned to meet the .25\% stiffness level and thereby avoid the separate requirements.

The previous absolute maximum allowable inter-storey deflection of $0.5 \%$ of the storey height has been retained in the new Code. This is in line with other codes. Apart from detailing problems which would otherwise occur, exceeding this limit would allow building sway which could start to cause undue alarm to occupants and could also cause column instability due to drift $(P-\Delta$ effect $)$.

For the calculation of building separations and the separations of nonstructural building elements a modification factor $v$ has been introduced.

For structures which dissipate seismic energy by ductile flexural yielding, the value of equals

$$
\nu=\frac{2.0 \mathrm{CI}}{\mathrm{C}_{\mathrm{d}}}
$$

For shear walls and tension braced structures $\nu=2$ and for prestressed concrete structures the factor has been increased by $40 \%$ over the value for ductile concrete structures.

The introduction of this factor is required because multi-term evaluation of 
the horizontal seismic loads would otherwise lead to serious anomalies for structures for which terms have been introduced which acknowledge superior behaviour of the structure during an earthquake as far as strength is considered.

The total displacement during an earthquake for systems with the same initial stiffness is only dependant on the factors $C$ and $I$ and the introduction of the modification factor achieves this.

The separation requirement is therefore proportional to

$$
C_{\mathrm{d}} \cdot \nu=x \cdot C_{d} \cdot \frac{C I}{C_{d}}=x \cdot C \cdot I
$$

To determine the deformation of members due to seismic loading, the design parameters such as moments of inertia, areas, etc., need to be determined and various assumptions regarding the parameters are necessarily approximate.

The code commentary supplies an acceptable simplified procedure for ductile frames in reinforced concrete and structural steel whereby moments of inertia are arbitrarily reduced by $25 \%$ to $30 \%$ to take account of cracking of cover concrete etc.

The moments of inertia for $\mathrm{T}$ and $\mathrm{L}$ beams can be adjusted upward to take account of $50 \%$ of the available slab width. This same consideration can also be applied to the effective width of shear wall flanges. This latter procedure is quite arbitrary but is justified because the $\zeta=2$ value is conservative in comparison with the value for ductile frames.

The 40\% increase for prestressed concrete is included to allow for the greater response for prestressed concrete compared to reinforced concrete with the same initial stiffness.

The code specifies that buildings shall be separated from each other $1 \frac{1}{2}$ times the sum of the computed deflections of the buildings multiplied by the respective modification factors.

This will then result in separation distances which are approximately equal to the present provisions.

Similar provisions are made for the separation of non-structural elements.

It should be noted that the specified separations are minimum provisions only. Especially for modern framed buildings, where the separation of elements will cause damping values to be much lower than before, these provisions are only satisfactory for moderate earthquakes.

\section{DYNAMIC ANALYSIS}

In this section of the code both the spectral modal analysis and the numerical integration response analysis are indicated.

The use of the latter is strictly confined to provide additional information on the behaviour of a structure and will therefore only be used by designers for unusual cases or for very important buildings. The problem with this method at the present time is that much of the outcome will depend on the input parameters.

Unfortunately, these parameters which include the mathematical model of the building, the chosen earthquake, the time history, the choice in the formation of plastic hinges, damping etc, are at this stage not sufficiently defined to warrant confidence regarding the overall design of the building.

It is acknowledged that for some buildings, important details could be highlighted by the use of this method and its use in the code is restricted to this aspect.

The procedure for the spectral modal analysis is outlined in the code.

The structure is to be designed for not less than the first three modes for each direction under consideration.

The structural design spectrum for each mode is taken as KC for each mode.

This means that the spectrum taken is a scaled value of the C curve in the code.

For practical purposes, a designer will use the value $I$ for $K$.

The achieved minimum base shear $\mathrm{V}$ is then to be scaled such that

$\mathrm{V} \min =0.9 \mathrm{C}_{\mathrm{d}} \mathrm{W}_{\mathrm{t}}$

This obviously means that the allowable minimum base shear is $90 \%$ of the static force analysis.

This recognises the value of the spectral modal analysis to the extent that for regular buildings, this analysis should provide a better idea on the actual load distribution.

A building design in accordance with this distribution will therefore be more ductile warranting a 10\% decrease in design base shear.

A further restriction is that at any level the shearing forces and overturning moments are not to be taken as less than $80 \%$ of the values obtained by the static analysis.

This clause is necessary because the spectral modal analysis sometimes gives load values at local levels which are low compared with the static analysis.

The discrepancy is caused by the fact that the spectral modal analysis neglects the effects of inelastic deformation of the building while the static method is more reliable in this regard.

\section{CONCLUSION}

The new proposed code is a significant step towards a more sophisticated seismic 
resistant design of buildings.

The various factors which have been introduced allow for a determined choice for designers which will create an awareness of relative merits of performance for various forms of structure, type of material etc.

The code embraces much of the latest available knowledge on the subject and will now enable all designers to incorporate the required standards of structural design in their buildings.

That many comments received by the committee show that engineers are very interested in this code.

It is obvious from these comments that some of these engineers have done a great deal of work in trying to assist the committee in their work.

Generally comments were favourable regarding the important aspects of the code and many suggestions were adopted in some form or another.

The next important refinement of a code such as this would be the application of a probabilistic approach. Some work in this area is already being done but this is still in an embryonic stage at present.

The fact that the code is now a means of compliance will ensure that further technical requirements and ideas will be readily incorporated in the design practices of New Zealand ensuring that our seismic resistant designs will constantly be surrounded with the latest "ring of confidence". Advertisements on our T.V. screens make us very aware of the fact that this is an important feature of our lives.

\section{ACKNOWLEDGEMENTS} are:

Members of the seismic loads subcommittee

\author{
R.I. Skinner (Chairman) \\ L.K. Arnold \\ G.W. Butcher \\ B.D. Cashin (S.A.N.Z.) \\ Dr D. Elms \\ L.W. Hurrell (Secretary) \\ O.A. Glogau \\ D. Kolston \\ Prof. N.A. Mowbray \\ Prof. R. Shepherd \\ Prof. P.W. Taylor \\ K. Williamson
}

\section{REFERENCES :}

Note: many of the references are recent articles published in the Bulletin of the New Zealand National Society for Earthquake Engineering, New Zealand Engineering, local symposium contributions etc, and the various references to books etc in these articles have not necessarily been referred to in this summary.

1. N.Z.S.S. 95, Part IV, Basic Design Loads.

2. N.Z.S.S. 1900, Chapter 8:1965, Basic Design Loads.
3. M.P. 12:1965. Commentary on Chapter 8 of N.Z.S.S. 1900 .

4. E.H. Hitchcock. "Rational Regulatory Control" Efficiency in Building Symposium Proceedings. Wellington 16 - 18 August 1973.

5. O.A. Glogau "The Objective of the New Zealand Seismic Design Code". Structural Design for Earthquakes, The University of Auckland Centre for Continuing Education 14 - 17 August 1972 .

6. R. Shepherd "Some aspects of the San Fernando Earthquake" N.Z. Engineering $197227(2), 57-63$.

7. City of Los Angles "Proposed Building Code Amendments - Group II - Resulting from the San Fernando Earthquake" April 28, 1972.

8. Skinner R.I. "Engineering Study of Caracas Earthquake, Venezuela", 29 July 1972. N.Z. D.S.I.R. Bull.191.

9. H. Umemura "Earthquake Resistant Design of Structures".

pages 97-102

"Lessons from the Tokachi-oki Earthquake".

10. "Recommendations on the design seismic forces for Japan" July 1972

11. G.A. Eily "A Philosophy of Seismic zoning". Bulletin of the N.Z. Society for Earthquake Engineering. Vol 4. No.1 March 1971.

12. Blakeley and Park. "Response of prestressed concrete structures to earthquake motions". New Zealand Engineering Feb. 1973.

13. G.W. Butcher "Steel Seismic Design" New Zealand Engineering: November 1971.

14. I.C. Armstrong "Capacity Design of Reinforced Concrete Frames for Ductile Earthquake Performance"

Structural Design for Earthquakes. The University of Auckland Centre for Continuing Education 14 - 17 August 1972 .

15. P.W. Taylor "Soil Mechanics Aspects of Seismic Design". Structural Design for Earthquakes The University of Auckland Centre for Continuing Education $14-17$ August 1972. (with list of references supplied at seminar).

16. H.B. Seed and I.M. Edriss "Influence of Soil Conditions on Building Damage Potential during Earthquakes". Journal of the Structural Division, A.S.C.E. Vo. 97, No. ST2, Proc. paper No. 7909 Feb 1971, p.p. 639-663.

17. Seismology Committee, Structural Engineers Association of California. Recommended Lateral Force Requirements and Commentary 1973.

18. T. Paulay. "Shear Walls in Seismic Design".

Structural Design for Earthquakes 
The University of Auckland Centre for Continuing Education 14 - 17 August 1972 .

19. Newmark and Rosenblueth

"Fundamentals of Earthquake Engineering" 1971 .

20. R.W.G. Blakeley. "A Review of the New Code Provisions for Separation of Elements and Buildings".

Bulletin of the New Zealand National Society for Earthquake Engineering Vol.7., No.3, Sept. 1974.

21. R.I. Skinner. "Earthquake - Generated Forces and Movements in Tall Buildings". Bulletin 166 of the N.Z. D.S.I.R.

22. R. Shepherd "The Seismic Design of Special Structures". New Zealand Engineering 15 December 1972.

23. J.P. Holldings. "Reinforced Concrete seismic design"

New Zealand Engineering 15 December 1971.

24. O.A. Glogau "Masonry Performance in Earthquakes" Bulletin of the New Zealand National Society for Earthquake Engineering Vo.7, No.4 December 1974. 